\title{
Effect of Air-powder Polishing on Dentin Adhesion of a Self-etching Primer Bonding System
}

\author{
Kozo NISHIMURA ${ }^{1}$, Toru NIKAIDO ${ }^{1}$, Richard M. FOXTON ${ }^{2}$ and Junji TAGAM1 ${ }^{1,3}$ \\ ${ }^{1}$ Cariology and Operative Dentistry, Department of Restorative Sciences, Graduate School, Tokyo Medical and Dental Univer- \\ sity, 1-5-45 Yushima, Bunkyo-ku, Tokyo, Japan \\ ${ }^{2}$ Department of Conservative Dentistry, Guy's, King's and St. Thomas' Dental Institute, Kings College London, London, UK \\ ${ }^{3}$ Member of the Center of Excellence Program, FRMDRTB at Tokyo Medical and Dental University, 1-5-45 Yushima, \\ Bunkyo-ku, Tokyo, Japan \\ Corresponding author, E-mail:nishimura.ope@tmd.ac.jp
}

Received October 12, 2004/Accepted January 27, 2005

\begin{abstract}
The purpose of this study was to evaluate the effect of air-powder polishing with sodium bicarbonate (SB) or crystalline cellulose $(\mathrm{CC})$ on the bond strength of a self-etching primer bonding system to dentin. Ground human dentin surfaces were prepared using 600-grit $\mathrm{SiC}$ paper. The teeth were divided into three groups according to dentin treatment: control, airpowder polishing with SB, and air-powder polishing with CC. The dentin surfaces were bonded with a self-etching primer bonding system, followed by a light-cured resin composite. $\mu$ TBS test and SEM analysis were performed. The results of $\mu$ TBS test indicated that air-powder polishing with SB affected bond strength to dentin, while that with CC did not influence bond strength. SEM observation of air-polished dentin surfaces showed that dentin surfaces air-polished with SB were roughened and covered with a smear layer, while those with CC were smooth and the smear layer was removed.
\end{abstract}

Key words: Air-powder polishing, Crystalline cellulose, Sodium bicarbonate

\section{INTRODUCTION}

Professional mechanical teeth cleaning has been widely accepted in clinical practice. The air-powder polisher can remove stains and plaque much more effectively than conventional methods such as hand instruments and a handpiece with a rubber cup, brush cone and abrasive paste ${ }^{1,2)}$. However, air-powder polishing with sodium bicarbonate visually roughens the surfaces of teeth and restorative materials ${ }^{3,4)}$. In addition, sodium bicarbonate powder is salty and contraindicated for patients who are sensitive to salinity.

Cleaning the cavity surface is an important clinical procedure prior to bonding of adhesive restorations, since contamination on the adhesive substrate is one of the clinical factors influencing bonding performance ${ }^{5,6)}$. Self-etching primer bond systems have recently become popular because of their easy handling and reduced technique-sensitivity ${ }^{7-9)}$. However, the dentin bonding strength of self-etching primer adhesive systems is influenced by the smear layer created by cutting instruments (such as rotary instrument $^{10)}$ ), air-abrasion ${ }^{11-13)}$, or laser abrasion ${ }^{14)}$. Also, the bond strength is affected by depth and tubule direction of dentin ${ }^{15-17)}$. Previous studies reported that bond strength to dentin using selfetching primer bonding systems was influenced by air-power polishing with sodium bicarbonat ${ }^{11,13)}$.

Recently, Horiguchi et $a l^{4)}$ used crystalline cellulose as a powder for air-powder polishing. Crystalline cellulose consists of round-shaped particles (25 $\mu \mathrm{m}$ in diameter) which have no taste, are scentless, and have no influence on the human body. Airpowder polishing using crystalline cellulose effectively removes plaque but causes much less damage to enamel, dentin, and resin composite compared with the use of sodium bicarbonate ${ }^{4)}$. However, there is no information on adhesion to dentin using airpowder polishing with crystalline cellulose.

Therefore, the aim of this study was to evaluate bond strength to dentin using a self-etching primer bonding system after air-powder polishing with sodium bicarbonate or crystalline cellulose. The null hypothesis was that no differences in bond strength exist among no-polishing, air-power polishing with sodium bicarbonate, and air-power polishing with crystalline cellulose.

\section{MATERIALS AND METHODS}

\section{Specimen preparation}

Experimental procedure is shown in Fig. 1. A total of 24 recently extracted human molars without caries were used in this study. They were obtained following a protocol reviewed and approved by an institutional review board and with the informed consent of the donors. The teeth were stored in tap water at $4{ }^{\circ} \mathrm{C}$ before use. The occlusal enamel was removed perpendicularly to the long axis of the tooth by means of a model trimmer under running water, and flat dentin surface was ground with 600-grit $\mathrm{SiC}$ paper under a stream of running water to expose 


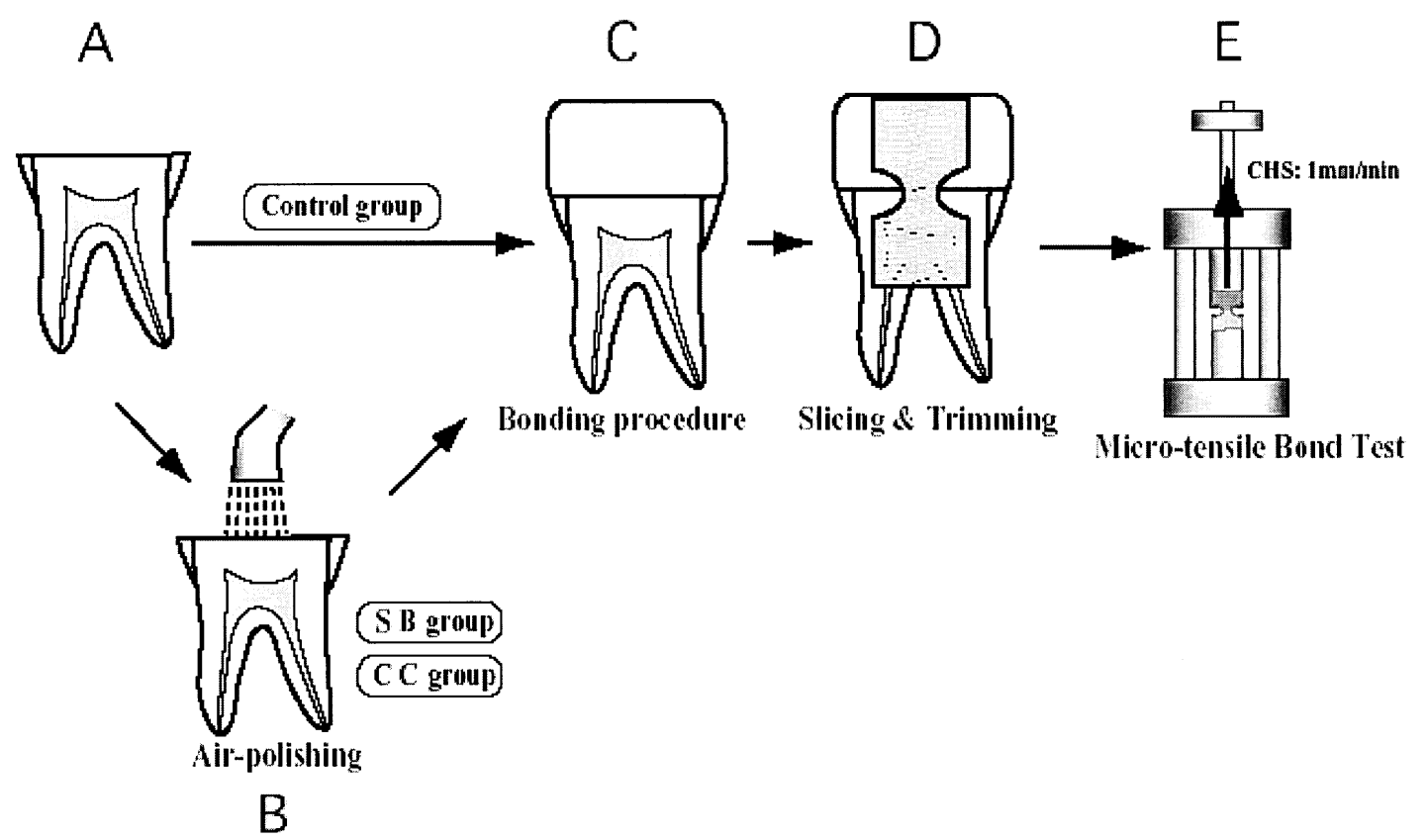

Fig. 1 Experimental procedure.

mid-coronal dentin. The teeth were then divided into three experimental groups according to dentin treatment, containing six teeth each. They were namely, Group 1: control group (no air-powder polishing); Group 2 (SB group): air-powder polishing with sodium bicarbonate powder (SB); and Group 3 (CC group): air-powder polishing with crystalline cellulose powder (CC). For SB and CC groups, the tip of the air-polisher (Air-Flow II, Shofu, Kyoto, Japan) was positioned approximately $5 \mathrm{~mm}$ from the tooth surface and operated for 20 seconds by directing a powder/water spray at an air pressure of $3 \mathrm{kgf} / \mathrm{cm}^{2}$ perpendicular to the tooth surface.

After the surfaces were rinsed for 10 seconds and gently air-dried, the specimens were treated with a self-etching primer bonding system (Clearfil SE Bond, Kuraray Medical, Tokyo, Japan) according to manufacturer's instructions (Table 1). After each adhesive resin was light-cured, a resin composite (Clearfil AP-X, Kuraray Medical, Tokyo, Japan) was built up in four layers to a height of $5 \mathrm{~mm}$ for $\mathrm{mi}$ cro-tensile bond test ${ }^{18)}$. Each layer was light-cured for 20 seconds. A visible light-curing unit, XL3000 (3M-ESPE, Minneapolis, MN, USA) was used for curing both the adhesive and resin composite. Specimens were then stored in $37^{\circ} \mathrm{C}$ water for 24 hours.

Eighteen teeth of resin-bonded teeth (six teeth from each group) were serially sectioned parallel to the long axis of the tooth into 7-8 slices, approximately $0.7 \mathrm{~mm}$ thick, using a low-speed diamond saw (Leitz 1600 Microtome, Leica Instruments $\mathrm{GmbH}$, Heidelberg, Germany) under water cooling. Bonded areas were isolated using a superfine diamond bur (ISO \#016, 16ff, GC, Tokyo, Japan) to create an

Table 1 Adhesive system used for bonding

\begin{tabular}{|c|c|c|c|c|}
\hline System & Composition & Batch No. & Instructions & Manufacturer \\
\hline Clearfil SE Bond & & & & $\begin{array}{c}\text { Kuraray Medical, } \\
\text { Tokyo, Japan }\end{array}$ \\
\hline
\end{tabular}

Primer

Bond
MDP, HEMA, water, multifunctional methacrylate, photoinitiator

MDP, HEMA, multifunctional methacrylate, photoinitiator, microfiller
011225

Apply $20 \mathrm{sec}$, dry

011228

Light-cure $10 \mathrm{sec}$

MDP 10-methacryloloxydecrl dihydrogen phosphate

HEMA 2-hydroxyethyl methacrylate 
hourglass configuration with a cross-sectional area of approximately $1 \mathrm{~mm}^{2}$. The final width and thickness of the bonded area were measured by means of a digital caliper to adjust the raw bonding data to an equalized bond per $1 \mathrm{~mm}^{2}$. The specimens were then attached to a testing device (Bencor-Multi-T, Danville Engineering, San Ramon, CA, 94583, USA) with a cyanoacrylate adhesive (Zapit, Dental Ventures of America, Corona, CA, USA) which in turn, was placed in a table-top material tester (EZ-test, Shimadzu, Kyoto, Japan) for tensile testing at a cross-head speed of $1 \mathrm{~mm} / \mathrm{min}^{18)}$.

Statistical analyses of tensile bond strength were performed using one-way ANOVA and Fisher's PLSD test at $95 \%$ level of confidence.

\section{SEM observation}

After bond strengths were measured, each fractured specimen was fixed in 10\% neutral buffered formalin for one day. The fractured surfaces of the samples were desiccated in vacuum and gold sputter-coated. They were then observed using a scanning electron microscope (SEM; JSM-5310LV, JOEL, Tokyo, Japan) to determine the fracture mode.

To observe the morphological characteristics of sodium bicarbonate powder (SB) and crystalline cellulose powder (CC), some particles of $\mathrm{SB}$ and $\mathrm{CC}$ were glued on the specimen holder for SEM analysis using bilateral vinyl tape and then gold sputtercoated.

To analyze the air-powder polished dentin by SEM, three dentin surfaces were prepared for each method in the same manner the bonded specimens were prepared. These specimens were rinsed with distilled water for 10 seconds and dried by air blowing. They were then desiccated in vacuum, and gold sputter-coated and observed using SEM according to previous studies ${ }^{11,12)}$.

Three human molars were used for SEM observation of dentin/adhesive interface prepared by each test method, after treatment with the self-etching primer bonding system. One bonded specimen of each group was cut vertically to obtain a crosssectional sample of the dentin/adhesive interface. The specimens were embedded in epoxy resin (Epon
815, Nissin EM, Tokyo, Japan). After curing the epoxy resin, the specimens were ground and polished with diamond pastes down to $0.25 \mu \mathrm{m}$. The specimens were subsequently etched with an argon-ion beam $(1 \mathrm{kV}, 0.2 \mathrm{~mA})$ for 270 seconds with an ELS1E (Elionix Ltd., Tokyo, Japan) prior to SEM examination ${ }^{19)}$.

\section{RESULTS}

\section{Micro-tensile bond strength}

The results of micro-tensile bond strength and fracture mode after testing are shown in Table 2. Bond strength to dentin treated by air-powder polishing with SB decreased compared to the dentin ground by 600 -grit $\mathrm{SiC}$ paper $(\mathrm{p}<0.05)$. On the other hand, bond strength to dentin treated by air-powder polishing with CC did not decrease compared to the dentin ground by 600 -grit $\mathrm{SiC}$ paper $(\mathrm{p}>0.05)$.

The modes of failure were classified into three types: (a) cohesive failure within bonding resin; (b) cohesive failure within/beneath the hybrid; and (c) mixed failure. Most of the failure patterns in the control and $\mathrm{CC}$ groups were classified as cohesive failure in bonding resin or mixed failure, but those in the SB group were failure within hybrid layer or dentin cohesive failure.

\section{SEM observation}

The SEM images of SB and CC powders are shown in Fig. 2. Particles of sodium bicarbonate powder are squarish and partially pointed crystals (about $100 \mu \mathrm{m}$ in the diameter). Crystalline cellulose particles, on the other hand, are round-shaped (about $25 \mu \mathrm{m}$ in diameter).

Representative SEM images of dentin treated with 600-grit silicon carbide paper, air-polished with $\mathrm{SB}$, and air-polished with $\mathrm{CC}$ were shown in Figs. 3 (a) -3 (c) respectively. For the dentin surface treated with \#600 silicon carbide paper, the ground marks by the abrasive paper were observed and dentinal tubules were covered with a smear layer. The dentin surface air-polished with SB was scooped out and roughened. As for the dentin surface air-polished with CC, no smear layer covered the surface and

Table 2 MTBS to dentin

\begin{tabular}{ccccc}
\hline Group & Number of specimens & MTBS $^{*}(\mathrm{MPa})$ & Range $(\mathrm{MPa})$ & Fracture Mode $^{* *}$ \\
\hline Control & 42 & $43.2 \pm 12.2^{\mathrm{a}}$ & $20.0-65.0$ & $\mathrm{~A}(35 \%), \mathrm{B}(42 \%), \mathrm{C}(23 \%)$ \\
$\mathrm{SB}$ & 45 & $36.6 \pm 8.0^{\mathrm{ab}}$ & $20.1-55.7$ & $\mathrm{~A}(25 \%), \mathrm{B}(23 \%), \mathrm{C}(52 \%)$ \\
$\mathrm{CE}$ & 43 & $44.1 \pm 12.4^{\mathrm{b}}$ & $21.9-62.6$ & $\mathrm{~A}(43 \%), \mathrm{B}(33 \%), \mathrm{C}(24 \%)$ \\
\hline
\end{tabular}

* Same superscript letters are significantly different $(p<0.05)$

**A: Cohesive failure within bonding resin;

B: Mixed failure;

$\mathrm{C}$ : Cohesive failure within/beneath hybrid layer. 

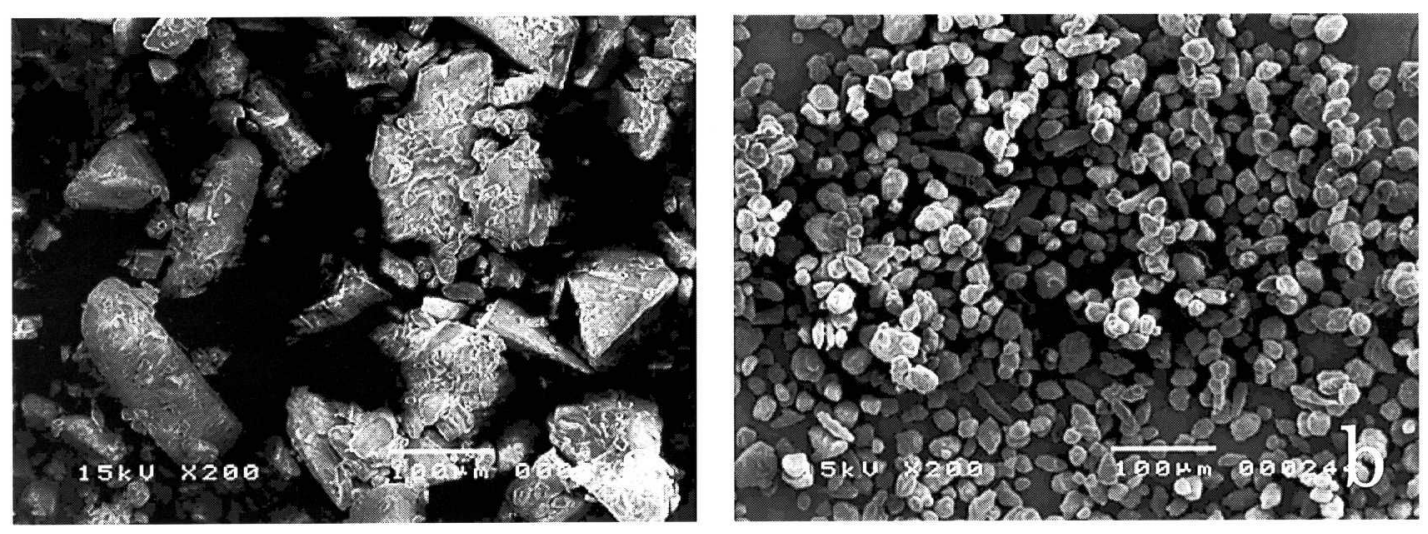

Fig. 2 SEM images of particles used for air-polishing.

a: Sodium bicarbonate powder showing point-shaped and large particles.

b: Crystalline cellulose powder showing round-shaped and fine particles.
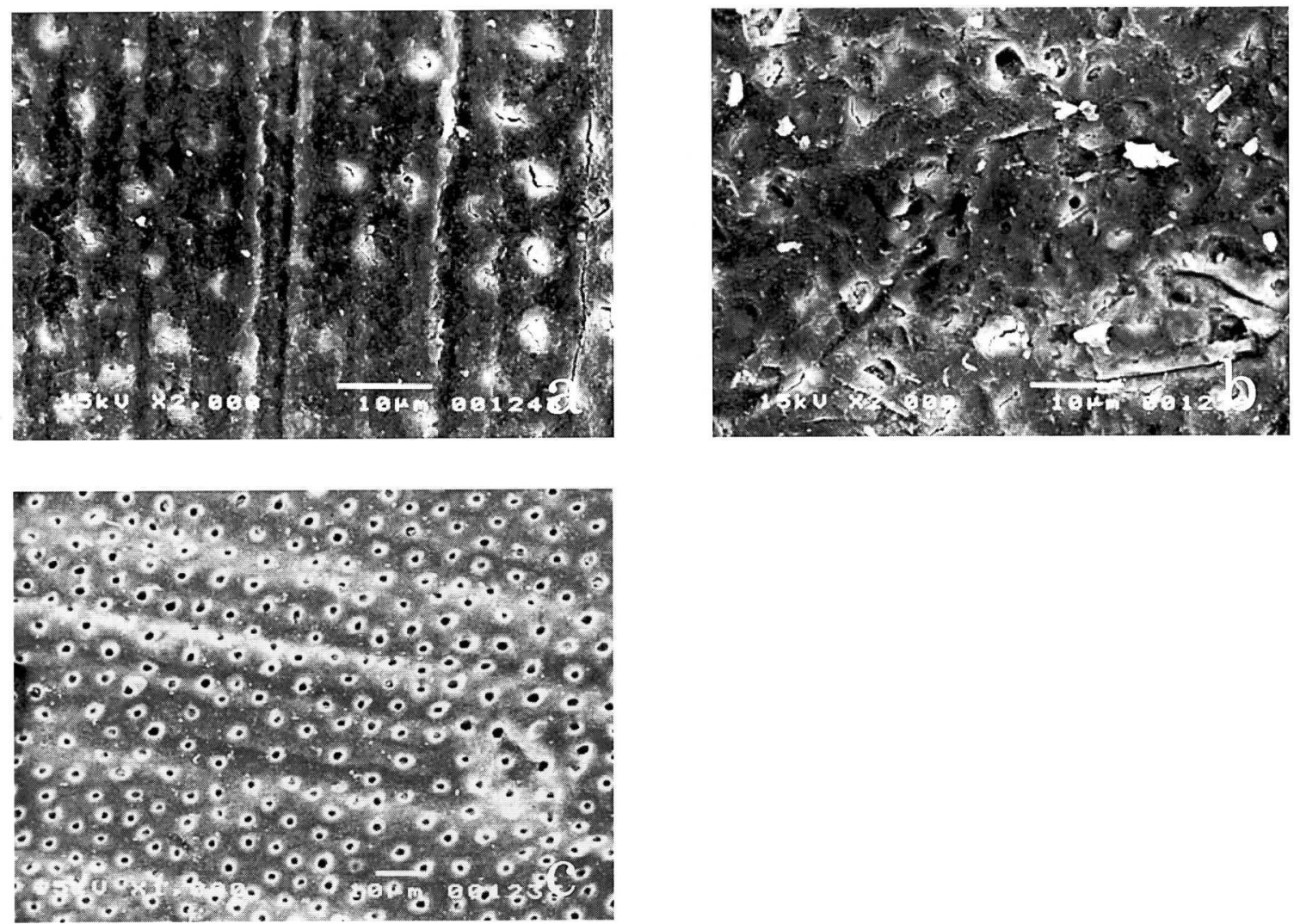

Fig. 3 SEM images of air-polished dentin surfaces.

a: Dentin surface abraded by \#600 SiC paper, showing many scratches left by the abrasive paper and the tubules covered by smear layer.

b: Dentin surface air-polished with sodium bicarbonate particles, showing a surface scooped out and roughened, the tubules partially opened and covered with smear by air-polishing.

c: Dentin surface air-polished with crystalline cellulose, showing a smooth surface and the tubules completely opened without any smear layer. 

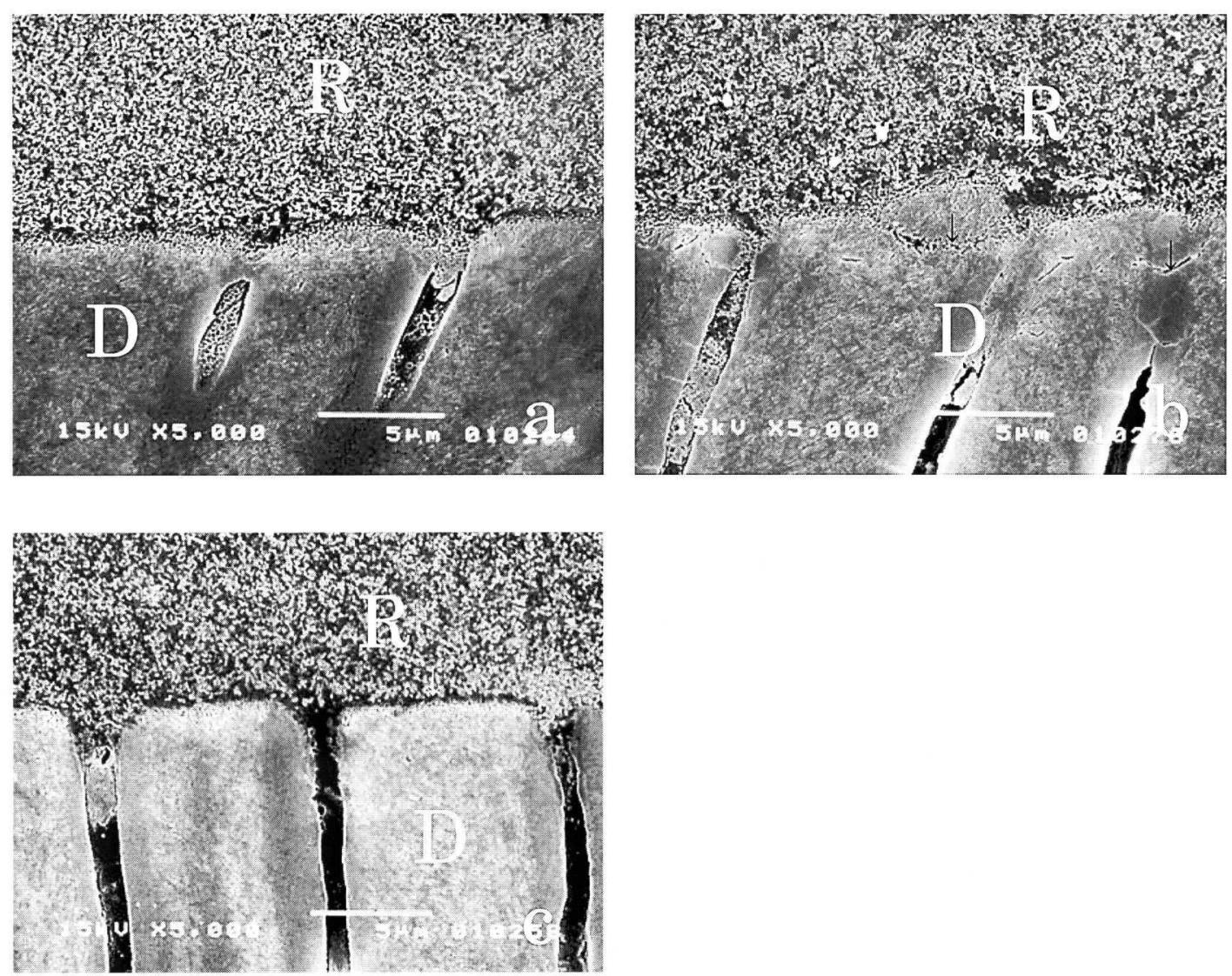

Fig. 4 SEM images of resin/dentin interfaces (R: composite resin; D: dentin; white arrow: hybrid layer).

a: Dentin surface abraded by \#600 SiC paper, showing a thin (under $1 \mu \mathrm{m}$ ) hybrid layer.

b: Dentin surface air-polished with sodium bicarbonate particles, showing rough and cracking dentin surface (black arrow).

c: Dentin surface air-polished with crystalline cellulose, showing a thin (under $1 \mu \mathrm{m}$ ) hybrid layer on a smooth dentin surface.

dentinal tubules were observed on a smooth surface.

SEM images of the dentin/adhesive interface treated with 600-grit silicon carbide paper, airpolished with $\mathrm{SB}$, and air-polished with $\mathrm{CC}$ are shown in Figs. 4(a)-4(c) respectively. These images demonstrate good adhesion between the dentin and adhesive resin for each group. However, the resin/ dentin interface treated by air-powder polishing with $\mathrm{SB}$ showed that the hybrid layer became irregular and unclear. Although the thickness of the hybrid layer of Clearfil SE bond was shown to be less than $1 \mu \mathrm{m}$, the hybrid layer of resin/dentin interface treated with \#600 abrasive paper or air-polished with $\mathrm{CC}$ was relatively clear and uniform.

\section{DISCUSSION}

Recently, self-etcting primer bonding systems have become popular in clinical practice. Self-etching primers combine the etching and priming steps without water rinsing. A self-etching primer demineralizes the smear layer and diffuses a short distance into the underlying dentin, resulting in the creation of a thin hybrid layer but a strong bond to dentin ${ }^{20-22)}$. While some studies reported that thickness of the smear layer influenced bond strength to $\operatorname{dentin}^{10,23,24)}$, Tay et al. reported that such a suspicion concerning thick smear layer interfering with the diffusion of self-etching primer was not confirmed ${ }^{25,26}$. Watanabe et $a l^{23)}$ reported that a smear layer wrought by low-grit abrasive paper, such as \#180 and \#400, was weak in mechanical properties hence leading to decrease in tensile bond strength.

The present study demonstrated that no specimens failed during specimen preparation for the micro-tensile bond strength test. However, the bond strength of Clearfil SE bond to dentin decreased following air-powder polishing with $\mathrm{SB}$, while airpowder polishing with $\mathrm{CC}$ did not influence the bond strength to dentin (Table 2). SEM observation of 
the air-polished dentin surfaces showed that SB scooped out and roughened the surface by the sharp and relatively hard corners of the SB powder particles (Figs. 2(a) and 3(b)), while the surface airpolished with $\mathrm{CC}$ was smooth because the particles were rounded in shape, soft, and fine (Figs. 2(b) and $3(\mathrm{c})$ ).

SEM observations of the resin/dentin interface showed that the hybrid layer became more irregular and unclear compared to the control. Air-powder polishing with SB might have caused the physical and/or chemical change of the collagen network, hence decreasing the permeability of self-etching primer bonding monomer ${ }^{11}$. Moreover, the buffer effect ( $\mathrm{pH}$ 8.3) of SB might still remain on air-polished dentin surface even after sufficient water spray ${ }^{11,12}$. With a relatively mild $\mathrm{pH}$ at 2.04 (according to manufacturer's information), the acidity of selfetching primer might have been chemically influenced by the effect of SB dissolved in water ${ }^{10)}$. As a result, the self-etching primer was not able to completely demineralize the smear layer caused by air-powder polishing with SB. These underlying factors might be the reason why bond strength to dentin decreased when treated by air-powder polishing with SB.

On the other hand, SEM observation of the dentin surface treated by air-powder polishing with $\mathrm{CC}$ revealed that the smear layer was almost removed and ground marks by \#600 abrasive paper remained partially (Fig. 3(c)). For the resin/dentin interface, SEM observation showed that the hybrid layer was smooth and uniform (Fig. 4(c)). Moreover, CC did not chemically influence the dentin surface because the powder is chemically stable. Therefore, self-etching primer could completely remove the smear layer and demineralize the underlying dentin air-polished with CC. Thus, the bonding resin of $\mathrm{CC}$ group might have penetrated more easily into the demineralized dentin compared to SB group and control group. This meant that air-powder polishing with $\mathrm{CC}$ did not influence the bonding strength of Clearfil SE Bond.

In the debonded specimens of the SB group, failures within or beneath the hybrid layer were observed in more than half of the specimens. On the other hand, in the $\mathrm{CC}$ and control groups, failures within or beneath the hybrid layer were observed in only approximately $25 \%$ of the specimens (Table 2 ). These observations suggested that the hybrid layer and the dentin structure beneath the hybrid layer created by air abrasion with SB might be weaker than those by air abrasion with $\mathrm{CC}$ and $\# 600 \mathrm{SiC}$ paper.

Clinically, self-etching primer bonding systems are often used in cases of cervical wedge-shaped defect, root dentin caries or on dentin surfaces after removal of temporary filling materials. In such cases, the dentin surface may be contaminated with debris, such as dental plaque and temporary materials. When a dentin surface is to be cleaned by air-powder polishing prior to treatment with self-etching primer bonding system, crystalline cellulose should be a useful agent based on the results of this study. On the other hand, the total-etch, wet-bonding technique using phosphoric acid is also popular in clinical practice. Since phosphoric acid produces more etching than self-etching primer, the thickness and microstructure of the hybrid layer created by a wetbonding system will be different from that by the self-etching primer bonding system ${ }^{27-29)}$. Therefore, further research is necessary when phosphoric acid etching bond systems are used.

\section{CONCLUSION}

When a self-etching primer bond system was used for dentin bonding, air-powder polishing with sodium bicarbonate powder affected bond strength to dentin. However, air-powder polishing with crystalline cellulose did not influence bond strength to dentin.

\section{ACKNOWLEDGEMENTS}

This research was supported by a Grant-in-aid from the Center of Excellence Program for Frontier Research on Molecular Destruction and Reconstruction of Tooth and Bone at Tokyo Medical and Dental University, Japan.

\section{REFERENCES}

1) Gerho LR, Barnes CM, Leinfelder KF. Applications of the air-powder polisher in clinical orthodontics. Am J Orthd Dentofacial Ortop 1993; 103: 71-73.

2) Sol E, Eapasa E, Boj JR, Canlda C. Effect of different prophylaxis methods on sealant adhesion. J Clin Pediatr Dent 2000; 24: 211-214.

3) Infeld $\mathrm{T}$. Comparison of the mechanical effects of toothbrush and standard abrasive on human and bovine dentin in vitro. J Clin Dent 2001; 12: 92-96.

4) Horiguchi S, Yamada T, Sugizaki J, Komatsu E, Nikaido T, Tagami J, Kuriyagawa T. Newly-designed prophylaxis method using air-powder abrasive system with crystalline cellulose. J J Conserv Dent 1999; 42: 536-544.

5) Bayindir F, Akil MS, Bayindir YZ. Effect of eugenol and non-eugenol containing temporary cement on permanent cement retention and microhardness of cured composite resin. Dent Mater J 2003; 22: 592-599.

6) Hibino $Y$, Kuramochi $K$, Harashima A, Honda $M$, Yamazaki A, Nagasawa Y, Yamaga T, Nakajima $H$. Correlation between the strength of glass ionomer cements and their bond strength to bovine teeth. Dent Mater J 2004; 23: 656-660.

7) Hayakawa T, Fukusima T, Nemoto K. Tensile bond strength of 4-META/MMA-TBB resin to ground bovine enamel using a self-etching primer. Dent Mater J 
2004; 23: 271-277.

8) Kanno T, Ogata M, Foxton RM, Nakajima M, Tagami $J$, Miura H. Microtensile bond strength of dual-cure resin cement to root dentin with different curing strategies. Dent Mater J 2004; 23: 550-556.

9) Hamano N, Lee MC, Ino S, Toyoda M. A study of the effects of self-etching primers on the polymerization of bonding agents using electron spin resonance (ESR) spectroscopy. Dent Mater J 2004; 23: 533-538.

10) Ogata M, Harada N, Yamaguchi S, Nakajima M, Pereira PNR, Tagami J. Effects of different burs on dentin bond strengths of self-etching primer bonding systems. Oper Dent 2001; 26: 375-382.

11) Nikaido $T$, Yamada $T$, Koh $Y$, Burrow MF, Takatsu T. Effect of air-powder polishing on adhesion of bonding systems to tooth substrates. Dent Mater 1995; 11: 258-264.

12) Nikaido $T$, Kataumi $M$, Burrow $M F$, Inokoshi $S$, Yamada $\mathrm{T}$, Takatsu $\mathrm{T}$. Bond strengths of resin to enamel and dentin treated with low-pressure air abrasion. Oper Dent 1996; 21: 218-224.

13) Nitta T, Maseki T, Nara $Y$, Tanaka H. Effect of airpowder polishing pretreatment on dentin bonding of self-etching primer adhesive system. J J Conser Dent 2003; 46: 451-473.

14) Van Meerbeek B, de Mink J, Matter D, Van Landuyt K, Lambrechts D. Microtensile bond strengths of an etch \& rinse and self-etch adhesive to enamel and dentin as a function of surface treatment. Oper Dent 2003; 28: 647-660.

15) Inoue $\mathrm{T}$, Takahashi $\mathrm{H}$, Nishimura $\mathrm{F}$. Anisotropy of tensile of bovine dentin regarding dentinal tubule orientation and location. Dent Mater J 2002; 21: 32-43.

16) Liu J, Hattori M, Hasegawa K, Yoshinari M, Kawada E, Oda Y. Effect of tubule orientation and location on the microtensile strength of bovine root dentin. Dent Mater J 2002; 21: 73-82.

17) Inoue S, Pereira PNR, Kawamoto C, Nakajima M, Koshiro K, Tagami J, Carvalho RM, Pashley DH, Sano H. Effect of depth and tubule direction on ultimate tensile strength of human coronal dentin. Dent Mater J 2003; 22: 39-47.

18) Sano H, Shono $T$, Sonoda H, Takatsu T, Ciucchi B, Carvalho R, Pashley DH. Relationship between surface area for adhesion and tensile bond strength -
Evaluation of a micro-tensile bond test. Dent Mater 1994; 10: 236-240.

19) Inokoshi S, Hosoda H, Harnirattisai C, Shimada Y. Interfacial structure between dentin and seven dentin bonding systems revealed using argon ion beam etching. Oper Dent 1993; 18: 8-16.

20) Watanabe I, Nakabayashi N, Pashley DH. Bonding to ground dentin by a phenyl-P self-etching primer. $J$ Dent Res 1994; 73: 1212-1220.

21) Chigira $H$, Yukitani $W$, Hasegawa $T$, Manabe $A$, Itoh K, Hayakawa T, Debari K, Wakumoto S, Hisamitsu H. Self-etching dentin primers containing phenyl-P. J Dent Res 1994; 73: 1088-1095.

22) Kimochi T, Yoshiyama M, Urayama A, Matsuo T. Adhesion of a new commercial self-etching/self-priming bonding resin to human caries-infected dentin. Dent Mater J 1999; 18: 437-443.

23) Watanabe I, Saimi, Y, Nakabayashi N. Effect of smear layer on bonding to ground dentin - Relationship between grinding condition and tensile bond strength. J Jpn Dent Mater 1994; 13: 101-108.

24) Inoue $\mathrm{S}$, Miura $\mathrm{Y}$, Sano $\mathrm{H}$, Kashiwada $\mathrm{T}$. Effect of $\mathrm{NaOCl}$ treatment on bond strength between indirect resin core-building and dentin. Dent Mater J 2002; 21: 343-354.

25) Tay FR, Sano H, Carvalho R, Pashley EL, Pashley DH. An ultrastructural study of the influence of acidity of self-etching primers and smear layer thickness on bonding to intact dentin. J Adhes Dent 2000; 2: 8398.

26) Tay FR, Carvalho R, Sano H, Pashley DH. Effect of acidity of smear layers on the bonding of a selfetching primer to dentin. J Adhes Dent 2000; 2: 99-116.

27) Wu J, Itoh $\mathrm{K}$, Yamashita $\mathrm{T}$, Tani $\mathrm{C}$, Hisamitsu $\mathrm{H}$, Wakumoto S. Effect of $10 \%$ phosphoric acid conditioning on the efficacy of a dentin bonding system. Dent Mater J 1998; 17: 21-30.

28) Imai $\mathrm{T}$, Itoh $\mathrm{K}$, Tani $\mathrm{C}$, Manabe $\mathrm{A}$, YamashitaT, Hisamitsu H, Wakumoto S. Effectiveness of simplified dentin bonding systems. Dent Mater J 1998; 17: 1-10.

29) Ogata M, Harada N, Yamaguchi S, Nakajima M, Tagama J. Effect of self-etching primer vs phosphoric acid etchant on bonding to bur prepared dentin. Oper Dent 2002; 27: 447-454. 